\title{
Imaging the high $b$-value anomalies within the subducting Pacific plate in the Hokkaido corner
}

\author{
Kei Katsumata \\ Institute of Seismology and Volcanology, Hokkaido University, North 10 West 8, Sapporo 060-0810, Japan \\ (Received July 21, 2006; Revised September 8, 2006; Accepted September 14, 2006; Online published November 15, 2006)
}

\begin{abstract}
The frequency-magnitude distribution ( $b$-value) for seismicity within the Pacific plate is not definitely homogeneous. An anomaly of $b$-value higher than 0.9 is detected within the descending Pacific plate in the Hokkaido corner. In the western Hokkaido, the anomaly exists at a depth of about $150 \mathrm{~km}$, which is directly beneath active volcanoes. In the eastern Hokkaido, the anomalies exist at approximately 200 and $300 \mathrm{~km}$ depths, which is tens of kilometers sideways from active volcanoes. The results obtained in this paper are more reliable than previous studies on $b$-value heterogeneity within descending plates, since I used a catalog homogeneous, both in time and space, which was obtained through re-examination of all seismograms and relocation of hypocentral parameters based on arrival times from fixed seismic stations.
\end{abstract}

Key words: $b$-value, Pacific plate, deep seismic zone, Hokkaido, volcanoes.

\section{Introduction}

The Gutenberg-Richter relation (Ishimoto and Iida, 1939; Gutenberg and Richter, 1944) is one of the wellfitted empirical relations in seismology: it represents the frequency of occurrence of earthquakes as a function of magnitude:

$$
\log _{10} N=a-b M,
$$

where $N$ is the cumulative number of earthquakes with magnitude larger than $M$ and $a$ and $b$ are constants. There are some explanations for different $b$-values: (1) high and low shear stresses cause earthquakes with low and high $b$ values, respectively (Scholz, 1968; Wyss, 1973; Urbanic et al., 1992; Schorlemmer et al., 2005), and (2) material heterogeneity (Mogi, 1962) and thermal gradients (Warren and Latham, 1970) also can cause changes in $b$-values. Some studies showed that the $b$-value is different for small and large earthquakes (Hamilton and McCloskey, 1997; Ikeya and Huang, 1997; Pacheco et al., 1992). Some interesting observations suggest that spatial variation in $b$-value of aftershocks is related to the rupture process of the main shock (Wiemer and Katsumata, 1999; Bayrak and Ozturk, 2004). There are some reports that spatiotemporal changes in $b$ values or a fractal dimension were detected prior to large earthquakes, e.g. Nakaya (2006), Murase (2004).

Low shear stress can cause high pore pressure (Wyss, 1973). Along the creeping zone of the San Andreas fault, earthquakes have high $b$-values because of possibly low stress, that is, high pore pressure. The $b$-value in the deep earthquake zones of Alaska and New Zealand is high at 95 $\mathrm{km}$ in depth (Wiemer and Benoit, 1996). This observation was interpreted that high pore pressure was due to dehydra-

Copy right(c) The Society of Geomagnetism and Earth, Planetary and Space Sciences (SGEPSS); The Seismological Society of Japan; The Volcanological Society of Japan; The Geodetic Society of Japan; The Japanese Society for Planetary Sciences; TERRAPUB. tion in the subducting slab. Therefore, high $b$-value anomalies possibly indicate a zone in a descending slab where fluids were produced, which may be a source of the magma generation for a volcanic arc. The low velocity zone in the mantle wedge was thought as a path of magma in the northeastern Japan (Zhao et al., 1992; Nakajima et al., 2001). Wyss et al. (2001) showed that the low velocity zone started around a volume with high $b$-value in the subducting slab at 140 to $150 \mathrm{~km}$ in depth, which supports the hypothesis of the magma generation at high $b$-value anomalies.

The purpose of this study is to map $b$-values of deep earthquakes within the descending Pacific plate and to make some discussions on a source of magma generation around the Hokkaido corner.

\section{Data}

A temporally homogeneous seismic catalog is the most important factor to the success of the $b$-value mapping. Seismicity data sets are very simple lists, including the origin time, latitude, longitude, depth of hypocenter, and magnitude. However, they reflect the output of an extremely complex and highly variable detection and reporting system. These complexities cause man-made changes in all seismicity data sets even if they are local, regional, or global (Habermann, 1987). In this paper, I have produced a new seismic catalog that is free from man-made changes, which allows for a more reliable analysis than was possible with previous studies.

I manually reexamined all waveform data, one by one, from 7112 earthquakes with $M \geq 3.0$, located by the seismographic network of the Institute of Seismology and Volcanology, Hokkaido University from January 1994 to February 2006. I considered the following three points in the reexamination process. First, 17 seismographic stations, which had already been installed in 1994, were selected (Fig. 1(a)). Any station installed after 1994 was not used 

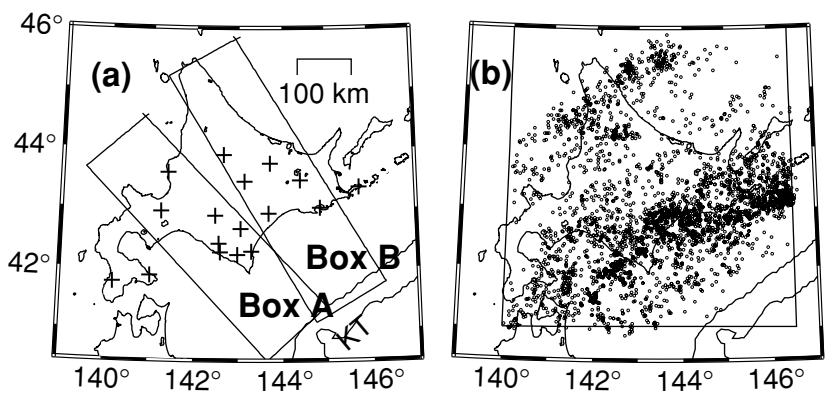

Fig. 1. (a) Hokkaido corner region. Crosses indicate seismographic stations used for reexamination of hypocenters in this study. Boxes A and B are the areas for cross-sections in Fig. 5. KT: Kurile Trench. (b) Earthquakes determined by the network in Fig. 1(a), which are the basis of our analysis. All hypocenters of 3337 earthquakes are located within the subducting Pacific plate, with $M \geq 3.3$, declustered, and occurred from January 1994 to February 2006. A rectangle indicates the study area of this paper.
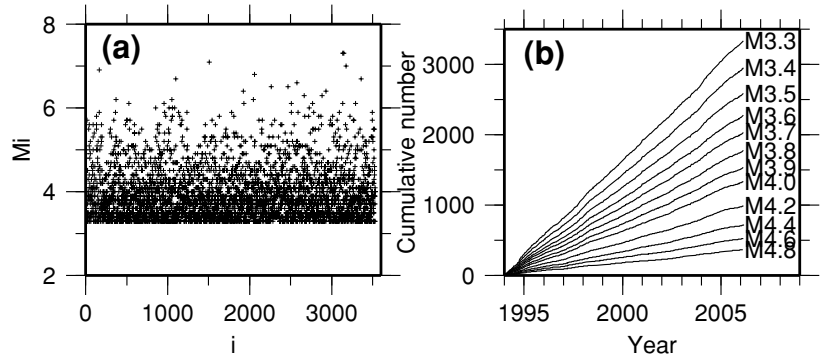

Fig. 2. (a) A $M_{i}-i$ plot for the 3337 earthquakes in Fig. 1(b) with horizontal axis indicating the $i$-th earthquake and vertical axis indicating its magnitude $M_{i}$ (Huang, 2006). (b) Cumulative number of earthquakes as a function of time. Magnitudes labeled each curve indicate the lower threshold of magnitude. For example the curve with a label of M4.0 is a cumulative number of earthquakes with M4.0 and larger.

in this process because installation of new seismic stations can cause man-made changes such as a magnitude shift and magnitude-scale compression or stretch. In addition, the station combination was fixed while calculating magnitude and reading $\mathrm{P}$ and $\mathrm{S}$ wave arrival times, in order to keep the condition of hypocenter calculation homogeneous. Finally, a single person carried out the reexamination of waveform data to avoid differences among individuals. See Katsumata and Kasahara (2004) for details of how to make the seismic catalog.

The Pacific plate subducts beneath the Hokkaido in a direction from southeast to northwest, along the Kurile Trench. Taking the location error of depth into account, I defined a new surface $5 \mathrm{~km}$ shallower than the upper surface of the deep seismic zone presented in figure 10(a) of Katsumata et al. (2003). From the new seismic catalog, I selected earthquakes deeper than the new surface in the southern part of the study area, and earthquakes deeper than $60 \mathrm{~km}$ in the northern part. Clustered events such as aftershocks and earthquake swarms were removed by Reasenberg's algorithm (Reasenberg, 1985). Although I plotted $b$-value using the original catalog before applying the algorithm, I found no substantial difference in the results. After occurrence of the two main shocks, the 2003 TokachiOki and the 2004 Kushiro-Oki earthquakes, all earthquakes
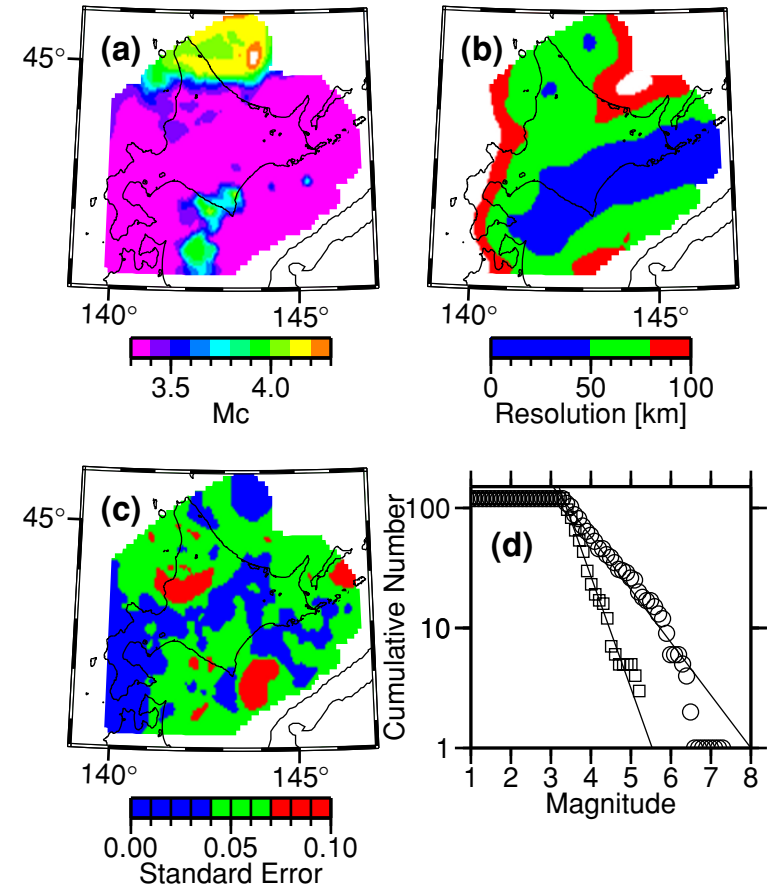

Fig. 3. (a) Magnitude of completeness, $M_{C}$. (b) Resolution defined by radii of circles sampling $N=120$ events at each node. (c) Standard errors of $b$-values mapped in Fig. 4. (d) Examples of frequency-magnitude distribution. Squares indicate the high anomaly of $b$-value at a node of $\left(42.51^{\circ} \mathrm{N}, 140.82^{\circ} \mathrm{E}\right)$ with $b=0.93 \pm 0.08$, and circles indicate the low anomaly at a node of $\left(42.31^{\circ} \mathrm{N}, 145.22^{\circ} \mathrm{E}\right)$ with $b=0.44 \pm 0.04$.

were deleted in the aftershock areas. The time window for deleting aftershocks was from the main shock to February 2006, which is the end of the seismic catalog. From the declustered catalog, I selected 3337 earthquakes with $M \geq 3.3$, which was the basis of our analysis (Fig. 1(b)). I plotted the number of earthquakes versus magnitude for the catalog to estimate the magnitude of completeness, $M_{C}$. I concluded that all earthquakes with $M=3.3$ and larger were located without fail, that is, $M_{C}=3.3$, up to the northern edge of $44.5^{\circ} \mathrm{N}$ (Fig. 3(a)). There, the hypocenters range from 10 to $250 \mathrm{~km}$ in depth. Further north, $M_{C}$ rises to $3.5 \leq M_{C} \leq 4.2$. Figure 2(a) shows a $M_{i}-i$ plot with horizontal axis indicating the $i$-th earthquake and vertical axis indicating its magnitude $M_{i}$ (Huang, 2006). This plot is useful to get a direct impression about how the magnitude of completeness varies with time and about possible artifact in the catalog. Since there is no systematic change in magnitude, the catalog is homogeneous. Plotting the cumulative number, I found that the reporting in this catalog does not change as a function of time for the wide range of magnitude, and there was no magnitude shift and stretch in this period (Fig. 2(b)). The hypocenter location errors are $5 \mathrm{~km}$ for the shallow portion, and to $10 \mathrm{~km}$ for the deep portion. They are about 10 times smaller than the anomalies I map.

\section{Analysis and Results}

I used the computer program ZMAP (Wiemer and Wyss, 1997) to make a $b$-value map (Fig. 4). Since the method is described in Wiemer and Wyss (1997), I only give an outline of the analysis. The study area was divided into grids with spacing of $0.1^{\circ}$ in latitude and longitude. A cir- 


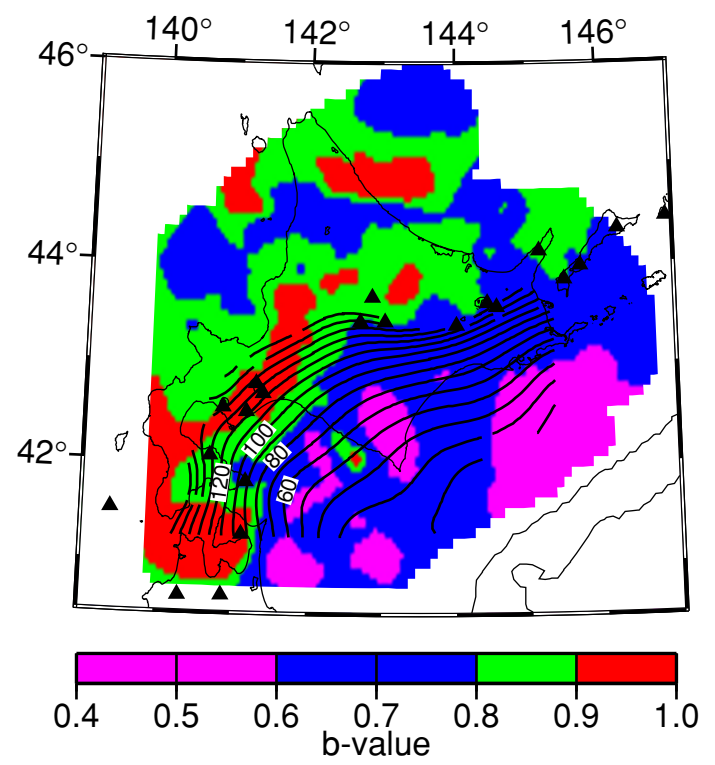

Fig. 4. Distribution of $b$-values for earthquakes within the subducting Pacific plate with $M \geq 3.3$ occurred from January 1994 to February 2006. In each sample $N=120$ events are selected at nodes separated by $0.1^{\circ} \times 0.1^{\circ}$. Solid triangles are active volcanoes, and the depth to the Pacific plate obtained by Katsumata et al. (2003) is indicated by contours every $10 \mathrm{~km}$.

cle was drawn around each grid point and its radius was increased until it included $N=120$ earthquakes. The radii for samples are less than $80 \mathrm{~km}$ in the study area (Fig. 3(b)). The $b$-value was calculated by using a maximum likelihood method (Bender, 1983) for the selected 120 earthquakes and the grid point was colored corresponding to the $b$-value. Although I mapped $b$-value with samples ranging from $N=80$ to 180 , I found no substantial differences in the results.

Examples of frequency-magnitude distributions selected in this way are shown in Fig. 3(d). The $b$-value map shows that the $b$-values for seismicity within the Pacific plate are not homogeneous. High anomaly zone with a $b$-value larger than 0.9 is imaged along contours of the upper boundary of the deep seismic zone from 100 to $150 \mathrm{~km}$ in depths between 140 and $142^{\circ} \mathrm{E}$. Volcanoes are located just above the anomaly in this zone. At the more eastern part of Hokkaido the high anomaly zone shifts toward deeper seismicity, and separates from the volcanic front. The standard errors are less than 0.04 in the anomaly zone and less than 0.06 in the surrounding volumes (Fig. 3(c)). Therefore there is a significant difference of $b$-value between $0.9-1.0$ in the anomaly zone and $0.6-0.8$ in the surrounding volumes.

The difference between the western and the eastern regions is clear in the cross-sections (Fig. 5). These maps were made by using hypocenters in Boxes $\mathrm{A}$ and $\mathrm{B}$ in Fig. 1(a), respectively, and the $b$-values were calculated at each node with $2 \mathrm{~km}$ spacing by using ZMAP. The high $b$ value anomalies are imaged around $150 \mathrm{~km}$ in depth in the western region. On the other hand, the anomaly is deeper than $200 \mathrm{~km}$ in the eastern region. Moreover, there is the second high $b$-value anomaly at a depth of $300 \mathrm{~km}$.

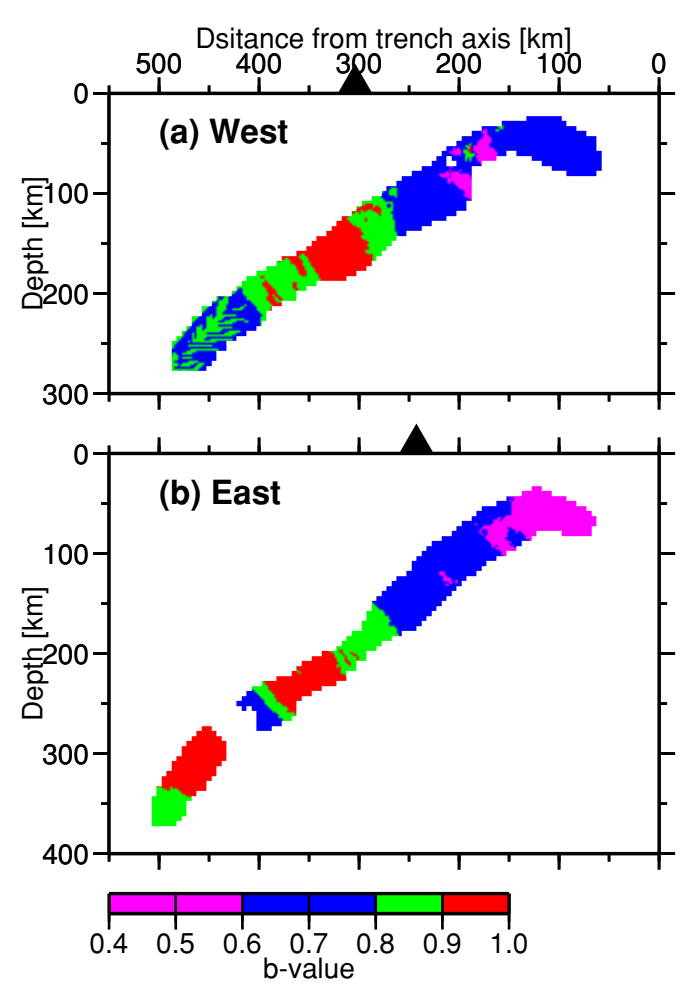

Fig. 5. Cross sections of $b$-value of earthquakes within (a) Box A and (b) Box B in Fig. 1(a). The $b$-values were calculated at each node with 2 $\mathrm{km}$ spacing by using ZMAP. Triangles indicate the volcanic front.

\section{Discussion and Conclusions}

Frohlich and Davis (1993) pointed out that they observed no systematic global variation of $b$-value with depth, and $b$ value changes are often over-interpreted and are subject to numerous numerical and systematic errors. Seismic catalogs used in previous studies on the $b$-value were usually suffered from a temporal man-made change in hypocenter and magnitude due to change in seismographic stations and data acquisition systems. These are the most crucial source of the systematic errors. My results overcome their criticism, since I examined all waveform data and calculated hypocenters and magnitude in the stationary condition. Therefore the high $b$-value anomaly zones I found are not artifacts caused by the numerical or systematic errors.

Wyss et al. (2001) found the high $b$-value anomalies at 140 to $150 \mathrm{~km}$ depth in the Tohoku region. The western region of our study is located north of the Tohoku region and the result is consistent with Wyss et al. (2001) on the depth of anomalies. However, the location of active volcanoes are different between the Tohoku and the western region of Hokkaido. In Tohoku, active volcanoes are not located just above the high $b$-value anomaly but are located tens of kilometers sideways from the volcanoes. In the western Hokkaido, the high $b$-value anomaly is mapped directly beneath active volcanoes. In Alaska and New Zealand subduction zones, the volcanic front is also located directly above the high $b$-value anomaly at a depth of 90-100 km (Wiemer and Benoit, 1996). Wyss et al. (2001) proposed the flow in the mantle wedge to explain the offset between the $b$-value anomaly and the volcanic front in Tohoku: the rising plume of magma from the $b$-value anomaly zone is deflected in a 
trenchward direction by the flow in the mantle wedge. If one follows this logic, the velocity of the flow is small in the western part of Hokkaido, and thus the volcanoes are located just above the high $b$-value anomaly zone.

On the other hand, I observed the offset tens of kilometers between the high $b$-value anomaly zone and the volcanic front in the eastern part of Hokkaido. Since this fact is same as Tohoku, the trenchward flow in the mantle wedge might be fast in the eastern Hokkaido. Katsumata et al. (2003) found a transition zone around $143^{\circ}-144^{\circ} \mathrm{E}$, which is located between the western and eastern Hokkaido. The subduction angle of the Pacific plate changes from $20-30^{\circ}$ to $40-50^{\circ}$ steeply at the transition zone. This change in the subduction angle is likely to cause the difference of the mantle wedge flow between the western and eastern Hokkaido.

Shorlemmer et al. (2005) reported that high $b$-values are observed in the areas of earthquakes with normal fault. In Hokkaido, the earthquakes with normal fault mechanisms are observed at intermediate depth. However, these earthquakes are not limited in the area with high $b$-value.

In summary, I found that a volume with high $b$-value anomaly exists around a $150 \mathrm{~km}$ depth in the western Hokkaido, and two volumes with high $b$-value anomaly exist around 200 and $300 \mathrm{~km}$ in the eastern Hokkaido. As pointed out by Wiemer and Benoit (1996) and Wyss et al. (2001), these anomalies appear to be the results of the dehydration process from the descending slab.

Acknowledgments. The comments from M. Imoto, an anonymous referee, and $\mathrm{K}$. Yomogida were very helpful in revising the manuscript. I thank colleagues at the Institute of Seismology and Volcanology, Hokkaido University for maintaining a seismographic network: M. Ichiyanagi, M. Okayama, H. Ishikawa, M. Takada, T. Yamaguchi, and H. Takahashi. I also thank Stefan Wiemer for the ZMAP program. GMT-SYSTEM (Wessel and Smith, 1991) was used for mapping data.

\section{References}

Bayrak, Y. and S. Ozturk, Spatial and temporal variation of the aftershock sequence of the 1999 Izmit and Duzce earthquakes, Earth Planets Space, 56, 933-944, 2004.

Bender, B., Maximum likelihood estimation of $b$-values for magnitude grouped data, Bull. Seismol. Soc. Am., 73, 831-851, 1983.

Frohlich, C. and S. Davis, Teleseismic $b$-values: or, much ado about 1.0, J. Geophys. Res., 98, 631-644, 1993.

Gutenberg, R. and C. F. Richter, Frequency of earthquakes in California, Bull. Seismol. Soc. Am., 34, 185-188, 1944.

Habermann, R. E., Man-made change of seismicity rates, Bull. Seismol. Soc. Am., 77, 141-159, 1987.

Hamilton, T. and J. McCloskey, Breakdown in power-law scaling in an analogue model of earthquake rupture and stick-slip, Geophys. Res. Lett., 24, 465-468, 1997.

Huang, Q., Search for reliable precursors: A case study of the seismic quiescence of the 2000 western Tottori prefecture earthquake, J. Geophys.
Res., 111, B04301, doi:10.1029/2005JB003982, 2006.

Ikeya, M. and Q. Huang, Earthquake frequency and moment magnitude relations for mainshocks, foresohocks and aftershocks: Theoretical $b$ values, Episodes, 20, 181-184, 1997.

Ishimoto, M. and K. Iida, Observations of earthquakes registered with the microseimograph constructed recently, Bull. Earthquake Res. Inst. Univ Tokyo, 17, 443-478, 1939.

Katsumata, K. and M. Kasahara, Making a temporally homogeneous seismic catalog, Geophysical Bulletin of Hokkaido Univ., 67, 213-224, 2004 (in Japanese).

Katsumata, K., N. Wada, and M. Kasahara, Newly imaged shape of the deep seismic zone within the subducting Pacific plate beneath the Hokkaido corner, Japan-Kurile arc-arc junction, J. Geophys. Res., 108(B12), 2565, doi:10.1029/2002JB002175, 2003.

Mogi, K., Magnitude-frequency relation for elastic shocks accompanying fractures of various materials and some related problems in earthquakes, Bull. Earthquake Res. Inst., Univ. Tokyo, 40, 831-853, 1962.

Murase, K., A characteristic change in fractal dimension prior to the 2003 Tokachi-oki earthquake $\left(M_{J}=8.0\right)$, Hokkaido, northern Japan, Earth Planets Space, 56, 401-405, 2004.

Nakajima, J., T. Matsuzawa, A. Hasegawa, and D. Zhao, Three dimensional structures of $\mathrm{Vp}$, Vs, and $\mathrm{Vp} / \mathrm{Vs}$ beneath the northeastern Japan arc: implications for arc magmatism and fluids, J. Geophys. Res., 106, 21843-21857, 2001.

Nakaya, S., Spatiotemporal variation in $b$ value within the subducting slab prior to the 2003 Tokachi-oki earthquake (M 8.0), Japan, J. Geophys. Res., 111, B03311, doi:10.1029/2005JB003658, 2006.

Pacheco, J. F., C. H. Scholz, and L. R. Sykes, Changes in frequency-size relationship from small to large earthquakes, Nature, 355, 71-73, 1992.

Reasenberg, P. A., Second-order moment of Central California seismicity, 1969-1982, J. Geophys. Res., 90, 5479-5495, 1985.

Scholz, C. H., The magnitude-frequency relation of microfracturing in rock and its relation to earthquake, Bull. Seismol. Soc. Am., 58, 399$415,1968$.

Schorlemmer, D., S. Wiemer, and M. Wyss, Variation in earthquake-size distribution across different stress regimes, Nature, 437, 539-542, 2005.

Urbanic, T. I., C. I. Trifu, J. M. Long, and R. P. Toung, Space-time correlations of $b$ values with stress release, Pure Appl. Geophys., 139, 449-462, 1992.

Warren, N. W. and G. V. Latham, An experimental study of thermally induced microfracturing and its relation to volcanic seismicity, J. Geophys. Res., 75, 4455-4464, 1970.

Wessel, P. and W. H. F. Smith, Free software helps map and display data, EOS Trans. Amer. Geophys. U., 72, 441, 445-446, 1991.

Wiemer, S. and J. P. Benoit, Mapping the $b$-value anomaly at $100 \mathrm{~km}$ depth in the Alaska and New Zealand subduction zones, Geophys. Res. Lett., 23, 1557-1560, 1996.

Wiemer, S. and K. Katsumata, Spatial variability of seismicity parameters in aftershock zones, J. Geophys. Res., 104, 13135-13151, 1999.

Wiemer, S. and M. Wyss, Mapping the frequency-magnitude distribution in asperities: An improved technique to calculate recurrence times?, $J$. Geophys. Res., 102, 15115-15128, 1997.

Wyss, M., Towards a physical understanding of the earthquake frequency distribution, Geophys. J. R. Astron. Soc., 31, 341-359, 1973.

Wyss, M., A. Hasegawa, and J. Nakajima, Source and path of magma for volcanoes in the subduction zone of northeastern Japan, Geophys. Res. Lett., 28, 1819-1822, 2001.

Zhao, D., A. Hasegawa, and S. Horiuchi, Tomographic imaging of P and $\mathrm{S}$ wave velocity structure beneath northeastern Japan, J. Geophys. Res., 97, 19909-19928, 1992.

K. Katsumata (e-mail: kkatsu@mail.sci.hokudai.ac.jp) 